\title{
Association between atherogenic dyslipidemia and fournier's gangrene
}

\author{
Derkan Akan ${ }^{1}$ \\ (iD)Ahmet Urkmez ${ }^{2}$
}

1. Department of Urology, University of Health Sciences, Sultan Abdulhamid Han Training and Research Hospital, Istanbul, Turkey. 2. Department of Urology, University of Health Sciences, Haydarpasa Numune Training and Research Hospital, Istanbul, Turkey.

http://dx.doi.org/10.1590/1806-9282.66.4.479

\begin{abstract}
SUMMARY
OBJECTIVE: We aimed to determine whether atherogenic dyslipidemia is associated with the disease and morbidity in our patients treated for Fournier's gangrene ( $F G)$.

METHODS: Sixty-two patients who were treated with the diagnosis of FG at our center between 2012 and 2017 were retrospectively screened. RESULTS: The triglyceride values of the patients who required reconstructive surgery were statistically significantly higher than those of the patients for whom wound debridement and primary suturing was sufficient (p:0.001). A total of 65.7\% of the patients had normal triglyceride values in the group in which wound debridement and primary suturing was sufficient, while this rate was $22.2 \%$ in the group of patients who needed reconstructive surgery; the difference was statistically significant (p: 0.002). The UFGSI score of those with triglyceride values higher than the normal range was statistically significantly higher (p:0.006). The cut-off point for the triglyceride value for which Fournier's gangrene was more morbid and the probability of reconstructive surgery need was significantly higher, i.e., >233mg.

CONCLUSION: Our study has demonstrated that atherogenic dyslipidemia, especially hypertriglyceridemia, is an important factor affecting morbidity and associated with high patient care costs after hospitalization and discharge in FG.
\end{abstract}

KEYWORDS: Fasciitis. Hypertriglyceridemia. Genitalia. Fournier gangrene. Genital diseases, male.

\section{INTRODUCTION}

Fournier's gangrene (FG) is a polymicrobial infection of the perineal and scrotal regions and manifests itself as a rapidly progressing necrotizing fasciitis. Predisposing factors include diabetes due to macroangiopathy and polyneuropathy, alcoholism, and immune-defects'.

Despite radical surgical debridement and treatment with broad-spectrum antibiotics, it has a high mortality and morbidity rate, and the course of the disease is unpredictable. It is essential to understand the pathophysiology and predisposing factors for early diagnosis and treatment. The Fournier's Gangrene Severity Index (FGSI) and Uludag Fournier's Gangrene Severity Index (UFSGI) are used to evaluate prognosis and stratify risks in these patients ${ }^{2}$.

In recent years, hypertriglyceridemia has been shown to be closely associated with atherosclerosis, endothelial dysfunction, and micro-angiopathy ${ }^{3}$. Atherogenic dyslipidemia (AtheroD) is a problem characterized by high triglyceride levels, especially when 
cholesterol levels are normal or low, and features very high atherogenicity ${ }^{4}$. In this study, we attempted to determine whether atherogenic dyslipidemias are associated with disease and morbidity in our patients treated for FG.

\section{METHODS}

After Institutional review board (IRB) approval was acquired from our university's ethics committee with the IRB number of "HNH EAH KAEK 2018/11", all patients who were treated with a diagnosis of FG at our center between 2012 and 2017 were retrospectively screened. Age, comorbidities, regularly used medications, laboratory analyses between admission and hospitalization, the UFGSI scores, wound cultures, medical treatments performed, surgical procedures performed, and hospitalization times of the patients were retrospectively recorded. Patients on medication affecting blood fat levels (antipsychotics, beta-blockers, bile acid binders, estrogen, corticosteroids, immunosuppressant, isoretinone, protease inhibitors, tamoxifen, thiazides) and patients with HgA1c $\geq 10 \%$ were excluded from the study. Also, the laboratory analyses and UFGSI scores of the remaining 62 patients were compared with several morbidity factors such as duration of hospitalization, antibiotic revisions, and need for reconstructive surgery.

In laboratory analysis, hemoglobin A1c (HbA1c), C-reactive protein (CRP), and hemogram parameters such as leucocyte (WBC), neutrophil (NEU), lymphocyte (LYM), and thrombocyte (PLT) counts were evaluated. In the evaluation of standard lipid profile, total cholesterol (TC), low-density lipoprotein (LDLC), high-density lipoprotein (HDL-C), and triglyceride (TG) levels were measured. TC, HDL-C, and TG levels were measured directly, while LDL-C values were calculated indirectly by the Friedewald formula. LDL-C levels were directly measured in those who had a TG level higher than $400 \mathrm{mg} / \mathrm{dL}$. Laboratory analyzes of all patients were performed on a full stomach within the first 24 hours of the patients' admission to our hospital.

All of our patients were hospitalized after being evaluated in the emergency clinic and empirically treated with ceftriaxone $2 * 1 \mathrm{gr} / 24 \mathrm{~h}+$ metronidazole $2{ }^{*} 0.5 \mathrm{gr} / 24 \mathrm{~h}$. All patients underwent extensive debridement by our urology department within the first 24 hours under antibiotic treatment. A culture sample was sent from debrided tissue and wound and the antibiogram was studied. Clinical inflammatory response and antibiogram results were evaluated by the infectious disease specialist within the first 72 hours. Based on that, it was decided if antibiotic therapy should be continued or revised. Primary wound suturing was performed in patients who had a clinical inflammatory response and no new tissue necrosis after extensive debridement and antibiotic treatment. Reconstructive secondary surgery was performed in patients with inadequate inflammatory control or new tissue necrosis. The patients who underwent vacuum-assisted closure (VAC) therapy and stoma treatment were followed up by the general surgery clinic, so they were excluded from the study.

\section{STATISTICAL ANALYSIS}

When evaluating the findings obtained in this study, IBM SPSS Statistics 22 for statistical analysis (SPSS IBM, Turkey) programs were used. The fit of the parameters to normal distribution was evaluated by the Shapiro Wilks test. In the evaluation of the data, descriptive statistical methods (mean, standard deviation, frequency), as well as the comparison of the quantitative data and Student's t-test were used for the comparison of the parameters which were normally distributed, and the Mann-Whitney U test was used for the comparison of the parameters that did not show normal distribution. Continuity (Yates) Correction was used to compare qualitative data. Logistic regression analysis was performed for multivariate analysis. The cut-off point was chosen based on the ROC curve analysis. Significance was evaluated as $p<0.05$.

\section{RESULTS}

The study was carried out with 62 patients aged between 37 and 86 years old. The mean age of the patients was $60.52 \pm 11.55$. The body mass index (BMI) values ranged from 22 to 40 with a mean value of $30.92 \pm 4.06$.

In $61.3 \%$ of our patients, antibiotic treatment was revised based on the reproduction in the wound culture and clinical course in consultation with the infectious diseases department. Escherichia coli, bacteriodes fragilis, corynebacterium, peptostreptococ, actinomyces turicensis, methicillin-resistant staphylococcus aureus, staphylococcus epidermidis, lactobacillus casei, staphylococcus lugdunencis, and candida 
albicans reproductions were observed in the wound cultures of our patients. The hospitalization period of the group with revised antibiotic treatment was statistically significantly longer (p: 0.001). The rate of reconstructive surgery need was $60.5 \%$ in the group in which antibiotic treatment was revised, whereas it was $16.7 \%$ in the group in which empirical treatment was sufficient. The UFGSI scores of the group in which antibiotic treatment was revised were higher but not statistically significant (p: 0.071). The rate of hypertriglyceridemic patients in the group of patients requiring antibiotic revision was higher than in the group of patients who did not require revision (60.5\% vs $41.7 \%$, respectively) (Table 1 ).

In $56.5 \%$ of our patients, adequate control was achieved through primary debridement and suturing, whereas $43.5 \%$ required reconstructive secondary surgery due to tissue necrosis. The TG values of those who required reconstructive surgery were significantly higher than those of the patients for whom primary debridement was sufficient (p: 0.001). While $65.7 \%$ of the cases had normal TG values in the group for whom primary debridement was sufficient, this rate was $22.2 \%$ in the group requiring reconstructive surgery, and the difference was statistically significant (p:0.002). Again, the UFGSI scores of those who required reconstructive surgery were statistically significantly higher $(\mathrm{p}=0.000)$ (Table 2$)$.

The TG values of our patients ranged from $84 \mathrm{mg}$ to $596 \mathrm{mg}$ with a mean of $238.74 \mathrm{mg} \pm 121.8$. According to the 2001 NCEP ATP III and 2012 Endocrine Society Guidelines, $53.2 \%$ of our patients were hypertriglyceridemic $^{5,6}$. The UFGSI score of those with triglyceride values higher than the normal range was statistically significantly higher (p:0.006). A ROC curve was drawn for the TG value to predict the need for reconstructive surgery. The area under the curve was 0.787 , and the standard error was 0.06. The area under the ROC curve was significantly higher than 0.5 (p: 0.001). The cut-off point determined for the TG value which predicts the need for reconstructive surgery was calculated as $>233$ $\mathrm{mg} / \mathrm{dL}$. The sensitivity of this value was found as $74.1 \%$, specificity as $82.8 \%$, positive predictive value as $76.9 \%$, and negative predictive value as $80.6 \%$ [Figure 1].

TABLE 1. EVALUATION OF AGE, BMI, DURATION OF HOSPITALIZATION, HBA1C, CRP, HEMOGRAM, BLOOD LIPIDS, UFGSI AND SURGICAL PARAMETERS IN THE GROUP REQUIRING ANTIBIOTIC THERAPY REVISION.

\begin{tabular}{|c|c|c|c|}
\hline & \multicolumn{2}{|c|}{ Antibiotic treatment revision } & \multirow[t]{3}{*}{$\mathrm{p}$} \\
\hline & Yes & No & \\
\hline & Mean \pm SD & Mean $\pm S D$ & \\
\hline Age & $60,71 \pm 10,5$ & $60,21 \pm 13,28$ & ${ }^{10} 0,869$ \\
\hline BMI & $31,32 \pm 4,31$ & $30,29 \pm 3,63$ & ${ }^{1} 0,338$ \\
\hline Duration of hospitalization (days) & $19,29 \pm 8,19$ & $12,46 \pm 6,51$ & ${ }^{1} 0,001^{\star}$ \\
\hline HbA1c & $9,28 \pm 3,15$ & $7,95 \pm 2,04$ & ${ }^{1} 0,049^{*}$ \\
\hline CRP & $12,83 \pm 9,45$ & $8,19 \pm 5,93$ & ${ }^{1} 0,036^{*}$ \\
\hline WBC & $14,79 \pm 5$ & $13,21 \pm 5,24$ & ${ }^{1} 0,240$ \\
\hline NEU & $11,92 \pm 5,23$ & $10,36 \pm 5,21$ & ${ }^{1} 0,256$ \\
\hline LYM & $1,62 \pm 1,06$ & $1,74 \pm 0,94$ & ${ }^{1} 0,659$ \\
\hline PLT & $285,76 \pm 79,6$ & $290,42 \pm 91,21$ & ${ }^{1} 0,833$ \\
\hline LDL-C & $132,15 \pm 29,49$ & $129,91 \pm 30,51$ & ${ }^{1} 0,785$ \\
\hline $\mathrm{HDL}-\mathrm{C}$ & $34,47 \pm 7,5$ & $36,38 \pm 7,92$ & ${ }^{1} 0,345$ \\
\hline $\mathrm{TC}$ & $201,13 \pm 39,68$ & $200,13 \pm 54,13$ & ${ }^{10} 0,933$ \\
\hline $\mathrm{TG}$ & $255,53 \pm 118,62$ & $213,71 \pm 124,99$ & ${ }^{1} 0,190$ \\
\hline \multicolumn{3}{|l|}{ TG group n(\%) } & \multirow{3}{*}{${ }^{2} 0,235$} \\
\hline Normal & $15(\% 39,5)$ & $14(\% 58,3)$ & \\
\hline Hypertriglyceridemic & $23(\% 60,5)$ & $10(\% 41,7)$ & \\
\hline UFGSI (median) & $3,24 \pm 1,76(3)$ & $2,63 \pm 1,61(2)$ & ${ }^{3} 0,071^{\star}$ \\
\hline \multicolumn{3}{|l|}{ Surgery n (\%) } & \multirow{3}{*}{${ }^{2} 0,002^{*}$} \\
\hline Reconstructive surgery & $23(\% 60,5)$ & $4(\% 16,7)$ & \\
\hline Primary Debridement & $15(\% 39,5)$ & $20(\% 83,3)$ & \\
\hline
\end{tabular}

1 Student t Test. 2 Continuity (Yates) Correction. 3 Mann Whitney $U$ test. ${ }^{*} p<0.05$. Hemoglobin A1c (HbA1c), C-reactive protein (CRP), leucocyte (WBC), neutrophil (NEU), lymphocyte (LYM), thrombocyte (PLT), low density lipoprotein (LDL-C), high density lipoprotein (HDL-C), total cholesterol (TC) and triglyceride (TG) 
TABLE 2. EVALUATION OF AGE, BMI, DURATION OF HOSPITALIZATION, HBATC, CRP, HEMOGRAM, BLOOD LIPIDS, UFGSI IN PATIENTS HAD A TRIGLYCERIDE VALUES BELOW AND ABOVE THE CUTOFF VALUE (233 $M G)$

\begin{tabular}{|c|c|c|c|}
\hline & \multicolumn{2}{|c|}{ Triglyceride values } & \multirow[t]{3}{*}{$\mathrm{p}$} \\
\hline & $\leq 233 \mathrm{mg}$ & $>233 \mathrm{mg}$ & \\
\hline & Mean $\pm S D$ & Mean $\pm S D$ & \\
\hline Age & $62,67 \pm 11,03$ & $57,54 \pm 11,81$ & ${ }^{10} 0,085$ \\
\hline $\mathrm{BMI}$ & $29,5 \pm 3,18$ & $32,88 \pm 4,38$ & ${ }^{1} \mathrm{O}, 002^{*}$ \\
\hline $\begin{array}{l}\text { Duration of hos- } \\
\text { pitalization (days) }\end{array}$ & $15,61 \pm 8,77$ & $18,08 \pm 7,38$ & ${ }^{10} 0,248$ \\
\hline $\mathrm{HbA1c}$ & $8,24 \pm 2,71$ & $9,5 \pm 2,88$ & ${ }^{10} 0,083$ \\
\hline CRP & $8,74 \pm 7,24$ & $14,2 \pm 9,27$ & ${ }^{10} 0,012^{*}$ \\
\hline WBC & $13,92 \pm 5,79$ & $14,54 \pm 4,07$ & ${ }^{10} 0,641$ \\
\hline NEU & $11,33 \pm 5,92$ & $11,3 \pm 4,23$ & ${ }^{10} 0,982$ \\
\hline LYM & $1,57 \pm 0,96$ & $1,81 \pm 1,08$ & ${ }^{1} 0,348$ \\
\hline PLT & $268,83 \pm 67,96$ & $313,5 \pm 96,82$ & ${ }^{1} 0,037^{*}$ \\
\hline LDL-C & $129,67 \pm 33$ & $134,15 \pm 22,86$ & ${ }^{1} 0,553$ \\
\hline $\mathrm{HDL}-\mathrm{C}$ & $35,64 \pm 7,31$ & $34,62 \pm 8,23$ & ${ }^{10} 0,608$ \\
\hline $\mathrm{TC}$ & $193,89 \pm 47,07$ & $210,23 \pm 41,99$ & ${ }^{1} 0,164$ \\
\hline UFGSI (median) & $4,06 \pm 1,09(4)$ & $6,35 \pm 3,32(5)$ & ${ }^{2} 0,002^{*}$ \\
\hline
\end{tabular}

1 Student $t$ Test. 2 Mann Whitney U. ${ }^{*}<0.05$. Body mass index (BMI), Hemoglobin A1c (HbA1c), C-reactive protein (CRP), leucocyte (WBC), neutrophil (NEU), lymphocyte (LYM), thrombocyte (PLT), low density lipoprotein (LDL-C), high density lipoprotein (HDL-C), total cholesterol (TC) and UFGSI (Uludag Fournier's Gangrene Severity Index)

FIGURE 1. ROC CURVE FOR TG IN THE DETERMINATION OF RECONSTRUCTIVE SURGERY

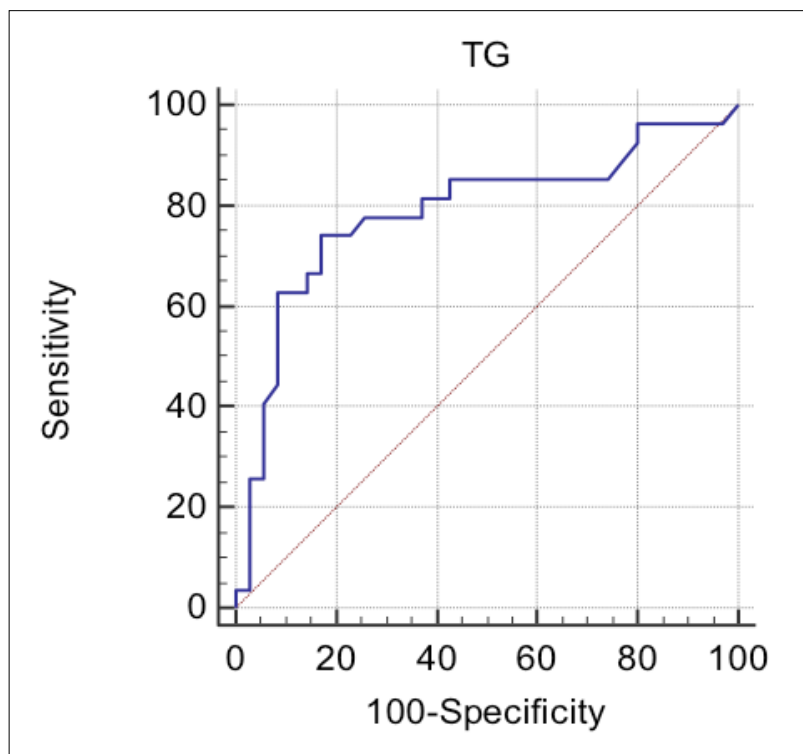

\section{DISCUSSION}

Fournier's Gangrene-associated mortality rates can reach up to $40 \%$ in the literature ${ }^{7}$. Although hyperbaric oxygen therapy has been popular in the last decade among the treatment methods, urgent radical surgical debridement and broad-spectrum antibiotic therapy are still considered the first-line treatment in $\mathrm{FG}^{\mathbf{8}}$. Very long hospitalizations, too many surgical procedures (especially genital/perinea debridement, orchiectomy, cystostomy, colostomy), mechanical ventilation, and other supportive care lead to considerably higher treatment costs. Early diagnosis, aggressive surgical interventions, and intensive postoperative care have undoubtedly controlled mortality rates. It is imperative to understand the pathophysiology and predisposing factors for early diagnosis and treatment.

Hypertriglyceridemia is frequently detected in routine laboratory screenings and accompanied by other dyslipidemias. Primary hypertriglyceridemia is associated with familial/hereditary causes whereas secondary hypertriglyceridemia is associated with nutrition, obesity, insulin resistance, endocrinological diseases, and alcohol consumption ${ }^{9}$. Hypertriglyceridemia may be adversely affected by endothelial dysfunction and lead to chronic low-grade inflammation, foam cell formation on the arterial wall, oxidative stress, and fibrinolysis/coagulation anomalies ${ }^{3}$. AtheroD usually refers to conditions where LDL-C levels are normal or low while atherogenicity is high ${ }^{4}$. The main clinical features in AtheroD are increased levels of TG and reduced levels of HDL-C ${ }^{4}$. When we look at the group represented by AtheroD, the risk of cardiovascular disease is higher than the general population. The data from the PROVE IT-TIMI 22, ACCORD-Lipid, IDEAL, and TNT studies have shown that elevated TG levels are associated with an increased incidence of death and major cardiovascular events ${ }^{4,10}$.

In a cross-sectional study, Schilling et al. ${ }^{11}$ evaluated cerebral vascular diseases by magnetic resonance imaging and found that they were statistically significantly associated with elevated plasma TG levels as opposed to other lipid fractions. Again in 2015, in a study by Shin et al. ${ }^{12}$, a significantly high correlation was found between serum TG levels and acute lacunar infarction in patients with DM. In another study, in the 6.5-year follow-up of 2207 adult patients without hypertension and prehypertension, the development of hypertension was predicted by waist circumference, CRP levels, and fasting TG along with diabetes in women in a multivariable logistic regression analysis $^{\mathbf{1 3}}$. This observation supports the fact that the inflammatory process contributes significantly to the development of hypertension through significant TG elevation. Also in our study, in patients with higher FG morbidity levels (those with high UFSGI, prolonged hospitalization, antibiotherapy change, and 
those who need additional reconstructive surgery), TG levels were significantly higher and HDL-C levels were lower but not significantly correlated with LDL-C or TC. The above study and our study support the evaluation of inflammation as a key mediator in microvascular infarction caused by TG.

Although many risk factors for FG have been reported in the literature, increased BMI is not among them. In a study in which patients were divided into two groups according to their survival status, no statistically significant difference was found between the BMIs of the two groups ${ }^{14}$. In our study, although the BMIs were higher in the group of patients who needed antibiotic revision and reconstructive surgery, this difference was not statistically significant. The findings of our study revealed that the BMI of patients was significantly higher in the hypertriglyceridemic group, which was also predicted to have higher morbidity, with a sensitivity of $74.1 \%$ and a specificity of $82.8 \%$.

In our study, the hospitalization durations and requirement for reconstructive surgery were statistically significantly higher, as expected, in the group in which antibiotic treatment was revised. TG values of those who required reconstructive surgery were statistically significantly higher than the TG values of the patients for whom primary debridement was sufficient. The UFGSI scores of those with triglyceride values higher than the normal range were statistically significantly higher. This data suggests that atherogenic dyslipidemia, especially TG elevation, may provide preliminary information about the course and morbidity of the disease in patients with FG. The need for antibiotic treatment revision and requirement for reconstructive surgery were significantly higher in patients with triglyceride values higher than the normal range. It can be predicted that FG patients with hypertriglyceridemia will have higher hospital stay and post-discharge care costs. In randomized controlled studies in which TG lowering treatments were applied, reductions in coronary events were reported ${ }^{15,16}$. These agents can be used in the follow-up and treatment of FG patients with hypertriglyceridemia.
There are some limitations to our study. Firstly, since clinical data were obtained retrospectively, selection and information biases may be possible. Secondly, nutritional status can affect TG levels significantly; however, our study did not collect data about the individuals' history of the most recent nutritional activity.

\section{CONCLUSION}

Despite today's advanced technology and treatment alternatives, FG is still a high-cost disease with high mortality and morbidity rates. While further studies are needed to demonstrate the pathophysiological mechanism of necrotizing fasciitis, we believe that atherogenic dyslipidemia, especially TG elevation, is significantly and consistently associated with disease progression, morbidity, and higher patient care costs.

\section{Ethical approval}

All procedures performed in studies involving human participants were in accordance with the ethical standards of the institution and/or national research committee and with the 1964 Helsinki declaration and its later amendments or comparable ethical standards.

\section{Informed consent}

Informed consent was obtained from all individual participants included in the study.

\section{Conflict of interest}

The authors declare they have no conflict of interest.

\section{Funding}

This research did not receive any specific grant from funding agencies in the public, commercial, or not-for-profit sectors.

\section{Author's contributions}

All authors contributed equally to this study.

\section{RESUMO}

OBJETIVO: Nosso objetivo foi determinar se as dislipidemias aterogênicas estão associadas à doença e à morbidade em nossos pacientes tratados para a gangrena de Fournier (GF).

MÉTODOS: Sessenta e dois pacientes tratados com o diagnóstico de GF em nosso centro entre 2012 e 2017 foram selecionados retrospectivamente.

RESULTADOS: Os valores de triglicérides dos pacientes que necessitaram de cirurgia reconstrutiva foram estatisticamente significativamente maiores em comparação com aqueles dos pacientes nos quais o desbridamento da ferida e a sutura primária foram suficientes 
(p:0,001); 65,7\% dos pacientes apresentaram valores normais de triglicérides no grupo em que desbridamento da ferida e sutura primária foram suficientes, enquanto que essa taxa foi de 22,2\% no grupo de pacientes que necessitaram de cirurgia reconstrutiva, e a diferença foi estatisticamente significativa (p:0,002). O escore UFGSI daqueles com valores de triglicerídeos acima da faixa normal foi estatisticamente significativamente maior (p:0,006). O ponto de corte para o valor de triglicérides pelo qual a gangrena de Fournier era mais mórbida e a probabilidade de necessidade de cirurgia reconstrutiva era significativamente maior foi >233 mg.

CONCLUSÃo: Nosso estudo demonstrou que a dislipidemia aterogênica, especialmente a hipertrigliceridemia, é um fator importante que afeta a morbidade e os altos custos associados ao cuidado do paciente após hospitalização e alta na GF.

PALAVRAS-CHAVE: Fasciite. Hipertrigliceridemia. Genitália. Gangrena de Fournier. Doenças dos genitais masculinos.

\section{REFERENCES}

1. Bönner C, Prohm P, Störkel S. Fournier gangrene as a rare complication after stapler hemorrhoidectomy. Case report and review of the literature. Chirurg. 2001;72(12):1464-6.

2. Yilmazlar T, Ozturk E, Ozguc H, Ercan I, Vuruskan H, Oktay B. Fournier's gangrene: an analysis of 80 patients and a novel scoring system. Tech Coloproctol. 2010;14(3):217-23.

3. Bansal S, Buring JE, Rifai N, Mora S, Sacks FM, Ridker PM. Fasting compared with nonfasting triglycerides and risk of cardiovascular events in women. JAMA. 2007;298(3):309-16.

4. Miller M, Cannon CP, Murphy SA, Qin I, Ray KK, Braunwald E; PROVE IT-TIMI 22 Investigators. Impact of triglyceride levels beyond low-density lipoprotein cholesterol after acute coronary syndrome in the PROVE IT-TIMI 22 trial. J Am Coll Cardiol. 2008;51(7):724-30.

5. Expert Panel on Detection, Evaluation, and Treatment of High Blood Cholesterol in Adults. Executive Summary of The Third Report of The National Cholesterol Education Program (NCEP) Expert Panel on Detection, Evaluation, And Treatment of High Blood Cholesterol In Adults (Adult Treatment Panel III). JAMA. 2001;285(19):2486-97.

6. Berglund L, Brunzell ID, Goldberg AC, Goldberg II, Sacks F, Murad MH, et al; Endocrine society. Evaluation and treatment of hypertriglyceridemia: an Endocrine Society clinical practice guideline. / Clin Endocrinol Metab. 2012;97(9):2969-89.

7. Ersay A, Yilmaz G, Akgun Y, Celik Y. Factors affecting mortality of Fournier's gangrene: review of 70 patients. ANZ J Surg. 2007;77(1-2):43-8.

8. Verit A, Verit FF. Fournier's gangrene: the development of a classical pathology. BJU Int. 2007;100(6):1218-20.
9. Rosenson RS, Brewer HB Jr, Chapman MJ, Fazio S, Hussain MM, Kontush A, et al. HDL measures, particle heterogeneity, proposed nomenclature, and relation to atherosclerotic cardiovascular events. Clin Chem. 2011;57(3):392-410.

10. Faergeman O, Holme I, Fayyad R, Bhatia S, Grundy SM, Kastelein IJ, et al; Steering Committees of IDEAL and TNT Trials. Plasma triglycerides and cardiovascular events in the Treating to New Targets and Incremental Decrease in End-Points through Aggressive Lipid Lowering trials of statins in patients with coronary artery disease. Am | Cardiol. 2009;104(4):459-63.

11. Schilling S, Tzourio C, Dufouil C, Zhu Y, Berr C, Alpérovitch A, et al: Plasma lipids and cerebral small vessel disease. Neurology. 2014;83(20):1844-52.

12. Shin DW, Lee KB, Seo JY, Kim IS, Roh H, Ahn MY, et al. Association between hypertriglyceridemia and lacunar infarction in type 2 diabetes mellitus. J Stroke Cerebrovasc Dis. 2015;24(8):1873-8.

13. Onat A, Can G, Örnek E, Sansoy V, Aydın M, Yüksel H. Abdominal obesity with hypertriglyceridemia, lipoprotein(a) and apolipoprotein A-I determine marked cardiometabolic risk. Eur J Clin Invest. 2013;43(11):1129-39.

14. Çitgez S, Demirdağ Ç, Özkaya M, Selçuk B, Erözenci A. Fournier's gangrene: analysis of risk factors affecting mortality in a tertiary urology referral center. J Urol Surg. 2019;6(3):196-200.

15. Le NA, Walter MF. The role of hypertriglyceridemia in atherosclerosis. Curr Atheroscler Rep. 2007;9(2):110-5.

16. Yuan G, Al-Shali KZ, Hegele RA. Hypertriglyceridemia: its etiology, effects and treatment. CMAJ. 2007;176(8):1113-20. 